\title{
Soil carbonation processes as evidence of tillage-induced erosion
}

\author{
J.R. Marques da Silva ${ }^{\mathrm{a}, *}$, Carlos Alexandre ${ }^{\mathrm{b}}$ \\ a Departamento de Engenharia Rural, Universidade de Évora, P.O. Box 94, P-7002-554 Évora, Portugal \\ ${ }^{\mathrm{b}}$ Departamento de Geociências, Universidade de Évora, P.O. Box 94, P-7002-554 Évora, Portugal
}

\begin{abstract}
Tillage-induced soil erosion or redistribution increases spatial variation of several soil properties and often reduces the productive capacity of soil resources. Our objectives were to identify the extent of this type of erosion by observing the changes in soil morphological properties in the field and analysing its possible effects on soil productivity. The study was initiated in 2001 and conducted at two irrigated sites located approximately at Terena, Alandrol, $80 \mathrm{~km}$ east of Évora, Portugal. They were planted to corn (Zea mays L.) during this study, but have a long history of agricultural use with a trend toward increasing intensity in recent years. Soils in the field studies are classified mainly as Calcaric Regosols, Calcaric Cambisols, Luvisols and small areas of Fluvisols. The amount of erosion was estimated by simulation and verified by describing the lithology and measuring soil carbonates. The presence of carbonates in the superficial Ap horizons of soils that were previously devoid of this compound, provide evidence of soil redistribution: (1) in soils derived from calcareous parent material, this is the result of a re-carbonation process; (2) in soils derived from non-calcareous parent material the presence of carbonates in the superficial Ap horizons results from a carbonation process. On both sites, A and B, approximately $17 \%$ of the soils sampled were either carbonated or re-carbonated. Carbonation and re-carbonation of soil profiles confirmed that tillage had redistributed the soil-ploughing layer over time. Decreased corn yield was also observed as slope increase. If current agricultural practices are continued in this area, a decrease in soil quality and maximum yield on higher slopes can be expected.
\end{abstract}

(C) 2004 Elsevier B.V. All rights reserved.

Keywords: Tillage-induced erosion; Soil variation; Yield variability; Soil quality

\section{Introduction}

Erosion is a severe form of soil degradation that leads to profound changes in soil characteristics and can significantly affect two critical soil quality functions - productivity and the capacity for environmental regulation or buffering. Speth (1994) estimated that about $80 \%$ of the world's agricultural land suffers from moderate to severe soil erosion and that an additional 10\% suffers from slight to moderate erosion. Similarly, Bongaarts (1994) estimated that in the 45

\footnotetext{
* Corresponding author. Tel.: +351-266-749823; fax: +351-266-711189.

E-mail address: jmsilva@uevora.pt (J.R. Marques da Silva).
}

years prior to $1993,17 \%$ of the world's land supporting vegetation suffered a decrease in agronomic value due to erosion.

Researchers have devoted a great deal of attention to soil erosion because of its impact on soil quality and consequently sustainability of agriculture production. Water and wind erosion have been the primary subjects for a large body of this research, but recently, increasing attention has been given to erosive processes associated with redistribution of soil during tillage (Lindstrom et al., 1992; Govers et al., 1993; Lobb et al., 1995). It is now recognized that each tillage operation can lead to soil redistribution and that as much as $4000 \mathrm{Mg} \mathrm{ha}^{-1}$ of soil can be redistributed by a single ploughing operation (Govers et al., 1994). 